\title{
QUEEN'S
UNIVERSITY
BELFAST
}

\section{"Your skin has to be elastic": The politics of belonging as a selected black academic at a 'transforming' South African university}

Belluigi, D. Z., \& Thondhlana, G. (2022). "Your skin has to be elastic": The politics of belonging as a selected black academic at a 'transforming' South African university. International Journal of Qualitative Studies in Education, 35(2), 141-162. https://doi.org/10.1080/09518398.2020.1783469

Published in:

International Journal of Qualitative Studies in Education

Document Version:

Peer reviewed version

Queen's University Belfast - Research Portal:

Link to publication record in Queen's University Belfast Research Portal

Publisher rights

Copyright 2020 Taylor \& Francis. This work is made available online in accordance with the publisher's policies. Please refer to any applicable terms of use of the publisher.

\section{General rights}

Copyright for the publications made accessible via the Queen's University Belfast Research Portal is retained by the author(s) and / or other copyright owners and it is a condition of accessing these publications that users recognise and abide by the legal requirements associated with these rights.

Take down policy

The Research Portal is Queen's institutional repository that provides access to Queen's research output. Every effort has been made to ensure that content in the Research Portal does not infringe any person's rights, or applicable UK laws. If you discover content in the Research Portal that you believe breaches copyright or violates any law, please contact openaccess@qub.ac.uk. 


\section{"Your skin has to be elastic": The politics of belonging as a selected}

black academic at a 'transforming' South African university

D. Z. Belluigi ${ }^{1 *}$ and G. Thondhlana ${ }^{2}$

This is the pre-print version, dated 9 June 2020. The Version of Record of this manuscript has been published and is available in International Journal of Qualitative Studies in Education accessible at https://doi.org/10.1080/09518398.2020.1783469. As this is a pre-print, a number of minor changes are in that version.

${ }^{1}$ School of Social Science, Education and Social Work, Queen's University Belfast, 69/71 University Street, Belfast, BT7 1HL, Northern Ireland; Chair for the Critical Studies of Higher Education Transformation, Nelson Mandela University. *d.belluigi@qub.ac.uk (Corresponding author) orcid.org/0000-0003-4005-0160 https://qub.academia.edu/DinaBelluigi

@DZBelluigi

https://www.linkedin.com/in/dinabelluigi/

${ }^{2}$ Department of Environmental Science, Rhodes University, South Africa. http://orcid.org/0000-0002-6141-3314 


\title{
"Your skin has to be elastic": The politics of belonging as a selected black academic at a 'transforming' South African university
}

\author{
A presumed indicator of change, in terms of the South African higher education \\ sector's racialised past, are the quantitative measures of numerical 'diversity' \\ within the academic staff composition at historically white institutions. To better \\ inform policy, academic development curricula and institutional culture, this \\ study focuses on macroaggressions related to the mis/recognition and \\ un/belonging of black academics who were selected for prestigious affirmative \\ 'accelerated development programmes' for transforming the academic staff \\ composition. Insights and narratives elicited via report-and-respond \\ questionnaires, reflective small group discussions and an arts-based method, \\ indicated that participants (a) experienced various microaggressions as members \\ of different communities within the institution, and as a result (b) negotiated \\ different identities according to social group norms, affordances and settings. The \\ study brings to the fore the complex social processes and agential consequences \\ of negotiating the politics of belonging in the looming shadow of legacies of \\ conflict and oppression.
}

Keywords: higher education, macroaggression, microaggression, inclusion, diversity, race, participation, equality, belonging, intersectionality

\section{Introduction}

Issues of inequality continue to plague higher education (HE) globally, from the starkly evident disparities of low participation, high attrition contexts through to wellresourced, high participation contexts (Marginson, 2016; Burke, 2012). Consistent with the international goal of addressing inequality of access to education (United Nations, 2015), are calls for fair representation and just participation of underrepresented groups in the demographics of students and staff. Parallel to this, the heterogeneity of the academic staff demographic is increasingly valued in 'diversity' rhetoric (Palmer, 2019) and 'internationalisation' rhetoric (Bollinger, 2007) for its contribution to intercultural competence, knowledge exchange and mobility in an increasingly globalised world. The 
presence of such heterogeneous actors raises political, economic and social tensions with threatened interests which may mitigate against structural or social change (Makhubela, 2018). The state of the transformation of academic staff is reflective of larger shifts in, and negotiations of, authority and power within societies.

Institutional racism in $\mathrm{HE}$ is prevalent within many national contexts, with academic staff remaining white dominant and whiteness dominated (Tate and Bagguley, 2017; Trejo, 2017). For instance, when mapping transformation in the UK context, gains made in the increased access of so-called 'black, Asian and ethnic minority' (BAME) students, should be set against the negligible proportionate increase to date in academic staff. The intersectional weight of race, gender and other markers of difference reveals itself across the academic ladder: from the racialized $\mathrm{PhD}$ pipeline which has been recently exposed as "broken” (Williams, Bath, Arday \& Lewis 2019), through to the composition of the professoriate, where less than $6 \%$ of professors are black, of which less than 20 are women (Equity Challenge Unit, 2017). Similarly, about $80 \%$ of full-time academic staff and full professors in the USA are white (National Center for Education Statistics, 2017). The academic staff composition in the UK and the US is disconcerting for national growth and change within those contexts, as they are not a true reflection of the demographic diversity of those populations. Of central concern is that such disparity may be reflective of the de/legitimation at play in the macro-curriculum of the academy both within those powerful contexts and geopolitically.

In South Africa, the terrain of higher education continues to be similarly dominated by and populated with white academics. White academic staff make-up more than half (53.2\%) of the academic work force (DHET, 2015) against a national demographic of $80.2 \%$ ('blacks'), $8.4 \%$ ('whites') ) $^{\mathrm{i}}, 8.8 \%$ ('coloureds'), $2.5 \%$ ('Indian/ 
Asians'). Disaggregated by university, the figures of white academics are substantially higher in 'historically white institutions' (HWI), the institutions which educated the white population during colonialism and apartheid, and which continue as the country's wealthier, better resourced and more prestigious institutions. This is despite the explicit macro-discourse of a rainbow nation underpinned by the dynamic regulation of transformative constitutionalism (Langa, 2006), where 'transformation' has become a dominant everyday signifier within policy, practice and scholarship within the HE sector. Underpinning the tensions between rhetoric and practice are differing and conflicting orientations to transformation (Belluigi \& Thondhlana, 2019), leading to the claim that there is "institutional resistance to transformation" within HWIs in South Africa (Booi 2016: 78). Critical studies in that context have identified the alienating effects of working in HWIs for black academics (Soudien, 2010; Suransky and van der Merwe, 2016), where misrecognition is further compounded by intersectional delegitimation of identities, communities and knowledge systems (Fataar, 2018).

Against this tide, South African black academics are looking for counter-spaces and platforms to express their trepidations about the so-called transformation of the academy (Khunou, Phaswana, Khoza-Shangase. \& Canham, 2019). Within critical higher education studies in that context, is a growing value of the positioning, insights and experiences of such academics as a basis for introspecting the grey areas of institutional culture (Keet, 2015), and particularly how to challenge the reproductive schooling of the hidden meso-curriculum of HWI. Such efforts are underpinned by a desire for engaged, impactful research which both critiques and informs substantive change within the academy for social justice (Keet and Belluigi, 2019).

This study particularly considers the experiences of the Fellows of the 'accelerated development' programmes which were implemented for the explicit 
purpose of diversifying the academic staff profile of HWIs while implicitly assuring the quality of the new entrants. As we discuss in the next section, the experiences of these Fellows offer (1) insider-outsider intersectional perspectives in understanding the majority culture of HWIs; (2) insights into the politics of belonging when heterogeneous individuals are located as representatives of 'diversity' and 'transformation'; and (3) the costs personally incurred in the name of higher education 'transformation'.

\section{Macroaggressions: Studying the politics of belonging in higher education}

Early in the 2000s, a number of the HWIs in South Africa initiated variously titled 'accelerated development programmes' (hereafter referred to as 'Programmes'). These Programmes were primarily funded by partners in the USA and were informed by their models for the inclusion of minority groups, even though the South African black population is overwhelming in the majority. Across their various iterations, the Programmes commonly included (1) a rigorous and competitive selection process for the top black and/or women academics ${ }^{\mathrm{ii}}$; (2) various support and training structures (mentorship, reduced teaching load, professional development); and (3) habitual evaluations against key performance indicators for a period of 2-3 years, prior to access to tenured positions along the academic hierarchy. The monitoring and evaluation of such Programmes centred on quantitative assessments of 'access and success' (e.g. DHET, 2015). Elements of these initial models have been retained in the recent nationally-funded, centralised programmes of the Staffing South Africa's Universities Framework (SSAUF): the 'New Generation of Academics Programme' (nGAP), 'Existing Academics Capacity Enhancement Programme', and 'Higher Education Leadership \& Management Programme' for black citizens and, where underrepresented, women. 
However, the increase in access of these select few black academics at HWIs has been recognised at governmental level as not having translated into the powerful participation of those actors, nor having substantially altered the racialized and gendered nature of South African HE (DHET, 2015). In part, this may be due to academic development discourses. The ontological turn of the last two decades saw a promotion of 'inclusion' and 'belonging' to address the affective challenges related to the success of those students considered 'diverse', who are most commonly 'historically disadvantaged' first generation black students. Imported from social mobility models, where diversity refers to the assimilation of minorities into a normative 'we', such understandings have been translated into promotional discourses of 'belonging' as one of the critical factors for staff retention in South Africa (Padayachee 2015; Belluigi \& Thondhlana, in press).

Belonging is defined as "an act of self-identification or identification by others, in a stable, contested or transient way" (Yuval-Davis, 2006, p. 199) where elements of inclusion and exclusion delineate the invisible borders of that collective. Individuals' adapt to and uphold the characteristics of the groups they belong to or identify with for the capital it lends them by association, or out of fear of being marginalised outside of its bounds. Membership or lack thereof, and positions within these groups, influences interpersonal relationships between individuals (Ahmed \& Stacey, 2001).

If the desired outcome of the national endeavour of 'transformation' is truly to disrupt the status quo of dominant common group white identification and Northern knowledge production, then the approaches of 'inclusion' and 'belonging' of black staff in HWIs are fundamentally problematic. Policy-makers and practitioners would benefit from analytical tools which unpack the politics of such belonging (Yuval-Davis, 2006), where the concerns relate to the participatory politics of academic citizenship and its 
related entitlements, status and power dynamics. Inherently linked to subjectification (Pierce 1969), macroaggressions are such a tool to enable study of "systemic, everyday racism [which is] used to keep those at the racial margins in their place" (Huber et al. 2015, p. 298). They demonstrate the ways in which commonplace events and relations, experienced by individuals, are systemically mediated by the processes and structures of institutionalized racism, which are underpinned by ideologies of the supremacy of dominant white groups and norms. Huber et al. (2015)'s model allows the charting of the situated nature of micro-, meso- and macro-relations of racism, from the interactional, to the institutional, to larger societal conditions.

Understanding the ways in which individuals assume identities and roles responsive to structural and institutional conditions, can enable researchers to identify and wrestle with the machinations of domination. Institutions play a central role (whether tacitly, explicitly or proactively) in the processes of identity formation and subjugation - projecting and rewarding certain values, norms and practices. Cultural identities are both projected on subjects and subjects project themselves into cultural identities, internalising their meanings and values, and aligning their subjective feelings to the objective world they inhabit to become a 'part of' the society. In contexts where such stability-reproduction is necessarily troubled - such as transforming societies attempting to address historic and systemic oppression - the politics of inter-group dynamics within such identity formation must come to the fore. The ways in which HE educates its academics, and in turn the ways in which the conditions for emancipation and democratisation of the system are created and affected, have long been a concern of the marginalised within (Freire, 1972; Spivak, 2008).

The long traditions of critical race studies and cultural studies warn of the dangers of researchers' assuming monolithic race cultures. It cannot be assumed that 
people who identity with or moreover are identified as the same race, gender, etc. possess the same cultural capital. An individual's relation to race and culture/s (and turn, capital/s) are shaped by a wide range of factors other than that category, that are often shared by people across different categories. Neither fixed nor autonomous, identities are formed and transformed in relation to the ways people are situated and positioned in the social systems they inhabit, with actors 'belonging' to and operating in different collectives in varied ways (Hall, 1990). The notion of difference enables nuanced experiences of marginalization to be explored, without negating the significance of group-based subordination and interlocking matrixes of domination (Collins, 1997). Intersectionality assumes that inequity is predicated upon differential valuation of identity categories which are socially, historically and culturally constructed (Christensen and Jensen, 2012). This analytical approach is premised upon the recognition of power hierarchies that affect agency and access to both resources and the dynamics of belonging.

Anti-discrimination measures which focus on clearly defined, overt or purposeful discrimination and threats, are not valid for addressing the subtle, unconscious or tacit racial prejudice and oppression which is difficult to detect and confront, such as systemic racism (Dovidio et al. 2002). The wide spectrum of racial and gender microaggressions range from: microassaults (name calling, threats or purposeful description) often carried out in subtle, automatic or unconscious forms; microinsults or layered assaults (with implications of negativity or deficiency based on race and its intersections with gender, class, sexuality, language, immigration status, phenotype, accent, or surname); microinvalidations (downplaying feelings, denying racism or white privilege); to cumulative assaults that take a psychological, 
physiological, and academic toll (Pieterse et al. 2012; Hall \& Fields, 2015; Huber \& Solorzano, 2015). When experienced as everyday indignities, these

have the lifelong insidious effect of silencing, invalidating and humiliating the identity and/or voices of those who are oppressed. Although their lethality is less obvious, they nevertheless grind down and wear out the victims (Sue, 2010, p. 66).

Compared to studies of industry and human resources generally, little analysis of microaggressions has been conducted within HEI (Young et al. 2015), despite HEIs being tasked as the drivers of the 2030 Agenda for Sustainable Development ${ }^{\mathrm{iii}}$. Significant negative outcomes of racial microaggressions, including mental health (Profit, Mino, and Pierce, 2000; Arday, 2018), have emerged in studies on predominantly white institutions in the USA (Pittman, 2012; Louis et al. 2016), and increasingly within the UK (Bhopal, Brown, \& Jackson, 2018; Bhopal \& Pitkin, 2018). Both are developed contexts where racial 'others' are the minority of their institutions and societies.

Less prevalent has been the academic study of the impact of such experiences of microaggressions on the particularity of academic identity in developing countries. The South African HE context presents a complex example of the challenge of addressing inequality in post-colonial contexts, where HE often retains the elitism and blinkeredness of settler colonialism. An HE sector "that continues to reproduce many of the fundamental discriminatory fault lines in society" (Keet \& Swartz, 2015), sharp disjunctures between opportunities, aspirations and self-interest reveal themselves when it comes to equality and quality. The ways of being, knowledge systems and languages of the non-academic communities from which black academics are chosen, are delegitimised within the academy in the both the national and global playing fields. This 
is the underpinning ontological and epistemic violence of othering - recognition of which has grown into an active national wrestling with im-possibility of decolonising the curriculum of the African academy (Heleta, 2016; Mbembe, 2015; Jansen, 2019). Those selected for 'inclusion' to universities are not a minority within the majority black population, but are positioned as such within HWIs which continue to dominate the sector, and the imaginaries of aspirants. Discourses of transformation which emphasize qualitative, substantive change in recognition of the historical legacies of oppression, have been found to have less traction in practice than compliance discourses from externally imposed equality regulation within such institutions (Belluigi \& Thondhlana, 2019). These translate into microinvalidations where selected Fellows are labelled as members of 'designated groups' and 'equity candidates' in pervasive narratives.

Although indicators for transformation in South African HE system are tilted towards quantitative measures, there are calls by policy-makers for an exploration of the lived experiences of academic staff as a pathway for social inclusion. This is a central feature of the self-regulating tool rolled out across the public institutions in 2018: 'The Transformation Barometer'. This paper contributes by exploring “experiences of inclusion/ exclusion and affiliation/ disaffiliation" for which the Barometer calls (Transformation Strategy Group, 2017), through eliciting insights into the politics of belonging of the select group of black academics who were chosen to participate in highly acclaimed 'accelerated development' programmes at an historically white institution in South Africa. In the following section, we outline the ways in which the study was methodologically informed, building on this initial discussion of studying higher education transformations. 


\section{Methodological matters}

This paper is broadly informed by Critical Race Theory (CRT) as an underpinning orientation for intellectual work challenging systems of racism and inequality. Scholars of CRT offer varied approaches for thinking about the relationships between social identity and social structures, and the ways in which power is re/produced in different forms through the coupling of race and space (Morrison, Annamma, \& Jackson 2017). Within CRT, it is argued that identity differences (race, gender, ethnicity, etc.) are influenced by space - where one's social location, within varying contextual intersections of difference, can condition one's experience and interpretation of space (Gillborn, 1995). Although utilised in other educational contexts (Ledesma and Calderon, 2015; Savas 2014), CRT has underpinned a relatively small number of qualitative studies of HE in the South African context (Erwin, 2012; Jawitz, 2012). Racial hegemony within the sector has showed itself to be persistent and untenable, despite the wide-ranging, explicit 'transformation' agenda for the sector which has been implemented through policy, meso-curricula changes, and agential re-positioning along the academic and managerial hierarchy (Vincent, 2008; Soudien, 2010; Cloete, 2014; Conradie, 2016).

Several tenets of CRT have informed our methodological choices, analytical sensibilities and categorisational representations. First, CRT recognises racism's pervasiveness as ordinary and commonplace, and an aspect of the everyday experiences of most black people (Delgado and Stefancic, 2001). Where these common everyday academic practices and their common sense ideologies are left unchallenged, institutions such as HEIs continue to consent, participate in and perpetuate problematic reproductions of both social and knowledge formations. This informed our discussion of the interrelatedness of micro-, meso- and macro-relations of racism within the HE sector 
in the introductory section above, and in the analysis of the particularity of this study below.

A second precept of CRT is that racial groups experience differential racialisation, most evident in the context of this study where black academic staff are viewed differently as the 'minority' in HWIs despite being in a majority-black national context, and therefore treated differently to their colleagues in response to various factors, including satisfying quotas and material interests. Third, proponents of CRT contend that "everyone has potentially conflicting, overlapping identities, loyalties, and allegiances" (Delgado and Stefancic, 2001, p. 9). This acknowledgement is reflected in the questions framed in our methods, and confirmed in the varied and rich receptions of membership and un/belonging of the various groups to which our participants engaged, as indicated in the headings of the next section.

The fourth central tenet is that the standpoint of those experiencing oppression (Delgado \& Stefancic, 2001) is most valid for challenging whiteness as the normative standard (Taylor, 1998). This informed the inclusion criteria of the study participants, and their positioning as collaborators within the projects' participatory and iterative analytical methodology, which we detail below. This inclusive iterative approach (1) was characterised by horizontal researcher-participant relations, where key informed insiders collaborated pragmatically and intellectually as central to, and active within, the research project; and (2) probed deeper into the complexity of issues to ensure the validity and nuance of the interpretations of the lived experiences of these heterogeneous participants. The participatory approach was the closest we could come to a research praxis of distributive justice in authorship, limited by the ethical considerations of protection of our participants' identities to mitigate against the professional risk they face ${ }^{\mathrm{iv}}$. 
Providing insights about the lived experiences of participation as an academic at historically white institutions in South Africa, the participants in this study were all recipients (hereafter referred to as 'Fellows') of the various formalised Programmes designed for the selection and inclusion of underrepresented 'talented' academics specifically black and/or women - into HWIs in South Africa. While much US research on affirmative action was critiqued for focussing on the reception of the in-group who are experiencing change, rather than the recipients of such programmes (Kravitz et al. 1997); the concern with South African studies of affirmative action programmes is that they narrow outcome-oriented monitoring and evaluation approaches which are neglectful of qualitative insights. It was due to the Fellow's discontent at such lack of critical enquiry and fatigue at the ineffectual impact of internal institutional research, that they encouraged the authors to undertake a participatory study to enable the Fellows to explore their differing receptions of group membership and experiences of microaggressions. Initially, we sought to include all of the 53 Fellows that had been part of the 2000-2017 duration of these Programmes within that HWI. However, 13 were not contactable and after discussion with the 10 who had recently joined the institution, it was decided mutually that they would not participate. The 27 Fellows who participated self-identified as six males, twelve females, ten black, five coloured, two Indian, three white. Exercising their agency, two participants did not indicate their race and nine did not indicate their gender. Fellows were from diverse disciplinary backgrounds and occupied academic positions across the professional hierarchy.

The Fellows were central authorities of the process to ensure that "those who are socially-marginalized... determine what is critical” (Berry, 2017, p. 63). The study focus was on the significance of experiences of macroaggression for those supposed 
'beneficiaries' of the Programmes, concurring with the argument that "deliberate intention to discriminate is by no means a necessary requirement in order to recognize that an activity or policy may be racist in its consequences" (Gillborn, 2003, p. 498). Rather than a conventional researcher-respondent relationship, with a number of participants of higher academic positions than the authors, our interactions were characterized by critical dialogue on the issues of concern. As such, the data generation process followed a report-and-respond approach (Stronach \& Piper, 2004) structured into mixed method stages. The paper as a whole is reflective of the meaning and emphasis ascribed by the Fellows, with primary data from each of the four stages situated alongside existing literature and interwoven with interpretations within this paper.

Firstly, an online questionnaire was designed to elicit participants' responses of their sense of identification and belonging with respect to the following so-called communities: transformation groups, designated groups (representative of certain demographics), Programme Fellows, departments and institution. Participants chose from these statements to indicate their responses: "I feel I am seen as deficit or lacking in quality in some way by member of this group"; "I identify strongly as a member of this group"; "I am very much uncertain of my belonging in this group", and "I am unsure of my position in this group but it does not bother me that much”. Unlimited space was provided for narrative expressions about the relations, processes and activities which participants felt contributed to their sense of identification and belonging. In addition, the questionnaire elicited responses about the participants' perceptions and experiences of the institutional staff evaluation practices and their relation to the transformation agenda, substantive discussion of which can be found at Belluigi \& Thondhlana (2019). Descriptive statistics (proportions) delineated the 
questionnaire survey data; with the themes emerging from participants' narrative responses identified, summarised and analysed through an open coding process.

In the second stage, the same participants were invited to small group discussions to ensure co-construction of interpretations, to which 9 of the 27 actively participated. The authors presented interpretations of the responses around multiple identities, and experiences of institutional and departmental practices. The Fellows then deliberated the appropriateness of those initial interpretations, and substratal considerations were explored to extend and enrich the analysis.

The third stage involved an arts-based approach, where participants wrote reflections on postcards, which they addressed to the particular audiences which they wanted to hear the findings. Replacing visual imagery, each postcard had the printed words of the evocative metaphors which the Fellows' had articulated within their questionnaire responses: "alien space", "talk show", "training the dog", "elastic skin", "put into a pot", "crabs in a bucket", "family", "poster child", and "window-dressing".

Fourthly, follow up meetings and communications involved input and discussion of the dissemination of the findings, including this paper, with consideration given to the nature of the pathways to impact at the institutional and national level. At the time of publication, these have included policy briefings and presentations to university committees and the circulation of draft publications to key stakeholders at the national level.

To avoid perpetuating stereotypes (Erwin, 2012) and exacerbating existing toxic institutional dynamics which have required the masking of individual and institutional identities, and to address the politics of representation within the project (Belluigi, 2018), we have attempted throughout to be aware of the influence of our positionality in leading this study. One author's lived experiences, as a Fellow of such Programmes, 
provided invaluable solidarity with participants as an insider researcher; however reflexive distance was necessary analytically to acknowledge the nuances of differing intersectional experiences of racialisation from his own as a diasporic African male. The other author's illusions about the formative benefits of mainstream academic development, and the benevolence of similarly placed white women, was ruptured once participants shed light on the mis-fit of the evaluation approach to which they were subjugated. These experiences of discomfort, together with the experiences from a previous research project on which the authors had collaborated (Thondhlana \& Belluigi, 2016), emboldened us to explore this difficult terrain with our participants cognisant of our positional inadequacies; resisting the 'othering' of our academic peers (Clegg, 2009); and committed to the "hope that it helps in some way", as one of our participants articulated about this paper in an email correspondence.

\section{Participants' perceptions of the politics of belonging}

Institutions of higher education, as social spaces and spaces of social formation, provide conditions for multiple identities which can either be assumed, resisted, contested or potentially reconstituted. From the beginning of our interactions, many of the participants of this study problematized simplistic categorisation of group membership, with one articulating that it was "difficult to pin down a single sense of belonging". Another wrote more expansively about identification and belonging in the open-ended questionnaire,

I have belonged to different groups based on different personal needs. In social spaces I was drawn more closely and belonged to people who more or less shared my culture and background, black working class. Academically I was drawn and belonged to groups who had the same research interest and 
where I felt I had something to contribute. I got something different from each of the groups. I don't usually put myself in a box.

This complexity was indicated in the responses to the question of identification across the groupings, represented in Figure 1.

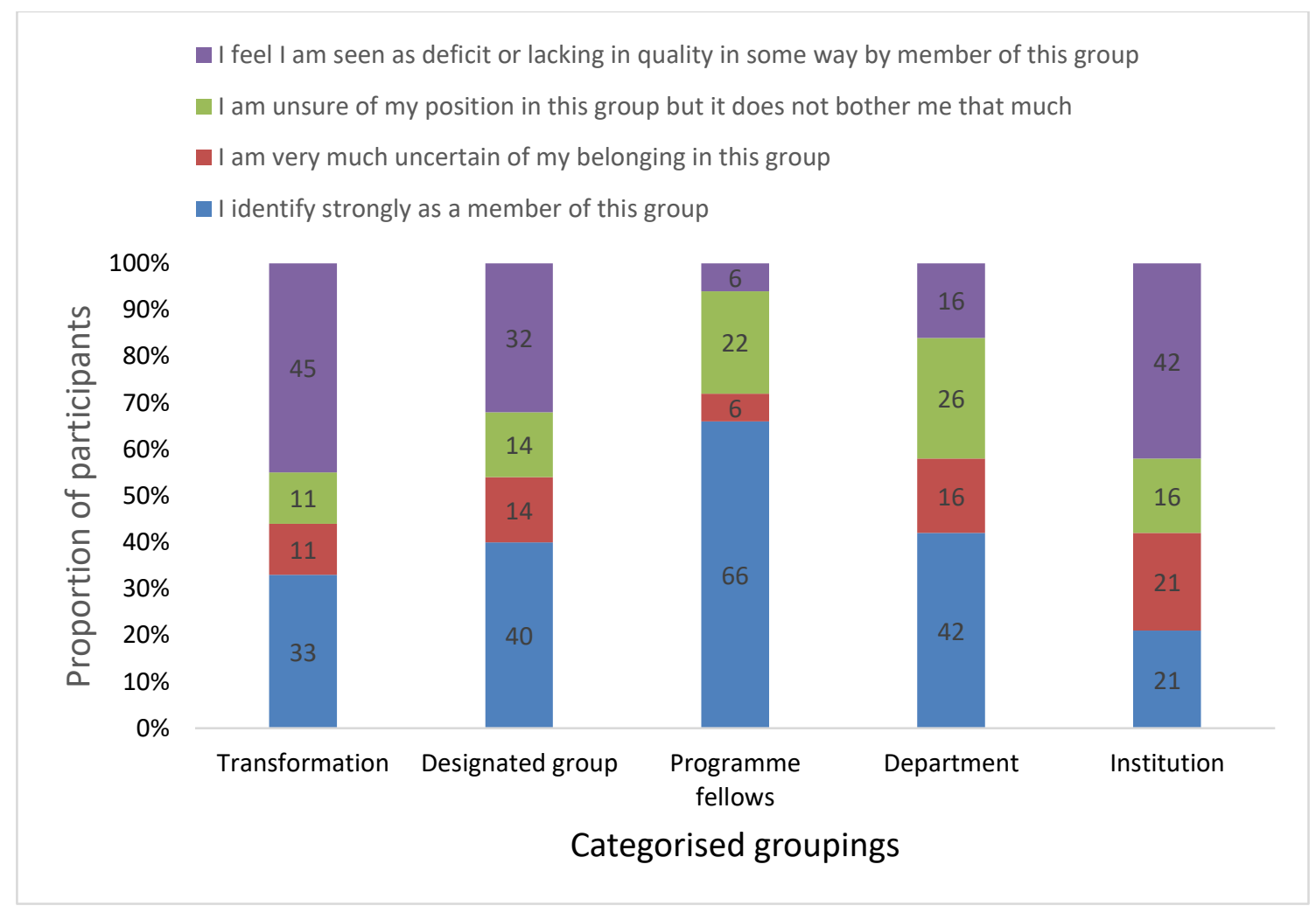

Figure 1: A visual representation of responses to positioning within the different groupings

Disaggregated by group, about two-thirds (66\%) of participants identified strongly as members of the Fellowship group, followed by their sense of belonging within their respective departments (42\%). There were clear extremes in those who strongly identified as members of a designated group (40\%) and as contributors to transformation (33\%) and those who felt deficit or lacking in quality in relation to those groupings (32\% and 45\%, respectively. Notably, very few participants $(21 \%)$ strongly 
identified as a member of the institution and a sizeable proportion felt they were seen as deficient or lacking in quality as an institutional group member (42\%). Interpretations of the qualitative responses are unpacked in more depth below, set alongside addition reflections of the Fellows from other stages in the process, and aspect of policy, discourse and literature to which they relate.

\section{The politics of belonging: As contributors to transformation}

The explicit desire of the Ministry of Education (DHET, 2017) and a stated objective of such Programmes, was that Fellows contribute to transformation. However, participating Fellows expressed much uncertainty about such positioning, expressed initially in the closed and open-ended questionnaire responses and later confirmed in each stage of the research process. For many, this related to how their "visual diversity" was being used as part of an institutional "numbers game", as one participant described it, to comply with minimum legislation requirements. Metaphors such as "token", "window dressing" and "poster child" were articulated by participants to visualise the ways they felt positioned for the "optics" within the institution.

I am still not sure how my diversity makes a contribution to the university if any, then just being a number that $\mathrm{x}$ [institution] prides itself with.

Those participants who had been past students within the HWI questioned whether they were legitimate change agents in the face of their enculturation as students. Chosen as part of "growing our own timber" (the title of some of the Programmes in Padayachee, 2015), it was realised in the small group discussions that there was a common perception among such Fellows that they had been selected as "low-risk alternatives" for preserving and sustaining the university's norms. 
Many participants were concerned that the aspects of their privilege that had made them eligible for selection (for some, being middle-class; for others, their parents' educational capital; and/or their school background) rendered them ineffectual for effecting change. Such influences "might concur with and wholly support opinions/practices that are contrary to transformation", as one participant described it. This related to a dominant concern expressed by participants, that the ignored criterion of class should be important when selecting Fellows for socio-economic transformation. By not recognising such privileges and capital, there was anxiety that Fellows' "talent" could easily be mythologised as what has been described in national discourses as 'black excellence'. Nearly all the Fellows expressed discomfort and distaste with such mythology as it created the perception that they were the exceptions to the rule of deficit. As with what has been described as the 'myth of the Supernegro' in a US study (Baldridge, 2016), such approaches rely on notions of individualism rather than structural repair and thereby neglect structural inequality.

Others who indicated they did not feel identification with this category, were those who had applied to the Programmes primarily for its professional opportunities of career advancement, and not as specifically "activists".

At X [HEI] I felt that not being actively involved in challenging institutional status quo put me in an awkward position, as not challenging in reality is interpreted as accepting things the way they are.

It emerged strongly that those participants who actively self-identified as agents of transformation within the institution, experienced the strongest alienation from their sense of self and purpose. This was partly due to the imposition of the conservative stasis of the cultures and structures at large, as we discuss in relation to departmental and institutional belonging below, and partly due to the awareness of how they were 
perceived by the dominant white culture and their own self-judgement about the limitations of their agency. This interpretation of the questionnaire responses, of internal conflict from external pressures and from double consciousness (Du Bois, 1903), was presented and confirmed during the small group discussions. Those who identified themselves in this category, added that they felt stronger affiliation with student politics and larger movements of social change occurring within the country beyond the borders of the academy. For such participants, their alienation had grown from deep disappointment at the constraints they experienced, frustration with the slow pace of change at the institution, and their exposure to harm within the HWI. As indicated in the excerpt from one of the small group discussions, below, the institutional responses to the campus protests from 2015 onwards, had brought the dangers of their political activism into sharp relief.

I think there are huge penalties for trying to effect transformation, especially in the last year and a half. Those who are trying to transform, who are challenging, who are refusing to remain silent - there are punishments in overt and covert ways. In often violent ways. So, I don't think it's possible. And that's not just us as academics, students as well. There are punishments for trying to challenge the system.

The idiom 'chipping away at the rockface', articulated by a participant within a questionnaire response and responded to by participants' postcard reflections, was seen as an apt evocation of a shared sense of futility and internal conflict of many of these more committed Fellows.

\section{The politics of belonging: As members of a 'designated group'}

The category 'designated group' is a term commonly used within the everyday discourse of institutions, influenced by the country's Employment Equity Act 
provisions for affirmative action of black people (Africans, Coloureds and Indians), women and people with disabilities. The majority of participants indicated discomfort with being located in relation to race and gender. Those markers of identity were resisted as reifying because, as two participants articulated, "identity is a lot more complex than legislation and bureaucratic processes allow" and is "multiple and complex and, therefore, messy". Problematising such categorisation, one participant narrated within the questionnaire that,

I am a HUMAN being, and those social categories have added no value to my life. If anything they have stereotyped me and others have continued to define me based on superficial categories that only have meaning in a particular socio-historical context.

A number of participants pointed to how the focus on race and gender, to the exclusion of other identities such as class (discussed above), rendered them as unimportant to transformation. For instance, one participant reported multiple subordinate-group identities which did not easily fit the prototypes of her respective identity groups (which she self-identified as 'queer', 'black', 'woman'). In the excerpt of her narrative below, an experience of what has been termed 'intersectional invisibility' emerges (PurdieVaughns \& Eibach, 2008).

My queer identity is an important aspect of who I am and how I experience this space, but it is often ignored or dismissed as not as important as race and gender.

Participants' narratives indicated that many of the Fellows were forced to negotiate the mutability of their identities and self-conceptions with their lived experiences intersecting at multiple levels. Recognition of such intersectionality was seen as necessary for imagining socially just relations against the whiteness of that institution. 
While individuals were categorised as part of the 'designated groups', they were also part of subgroups and often assumed superordinate identities and positions to get the best of every situation.

The majority of participants recognised the importance of the distinction of 'designated group' for ensuring external accountability for the institution's compliance to regulations of affirmative equity goals. However, the persistence of the distinction from mainstream colleagues and within mainstream discourse in the institution, amounted to negative 'labelling'. The distinction maintained the conditions for 'othering' and marginality (as "outsiders", "newcomers" and "special cases", as identified in participants' narratives) in the departmental and institutional communities at that HWI. Such 'default identities' are indicative of a lack of reflexivity about norms of privilege of power (Kitzinger \& Wilkinson, 1993; Walker, 2005). In the South African educational context, these deficient notions are pervasive despite being actively critiqued (Coleman, 2016). They typify discourses around the entry of black students and staff in the HE sector, often labelled as 'underprepared', 'first generation', 'underprivileged', and 'disadvantaged' (McKay \& Devlin, 2016; O'Shea et al. 2016). These deficit discourses persisted to the extent where they become entrenched as everyday microinsults. As such, within the questionnaire ranked statements $32 \%$ of the Fellows indicated they believed they were seen as deficit 'designated groups'.

There was a feeling that a black person can't come straight-away and start lecturing, he has to be taught by 'us first'... The foundational thinking around the Programme must be rethought as this bad impression it gives of Black people will be perpetuated, especially when it puts in Black people already with $\mathrm{PhDs}$ (from other institutions) on its x [Programmes], and not White counterparts, even those with a Masters. 
Such insights confirmed and lend support to the myriad of other studies within the South African context and more broadly, which point to how integration narratives serve to enforce pathologisation of black identity. The evocation of Steve Biko's concept of 'artificial integration' (1986) within Bazana and Mogotsi's (2017) study of the experiences of black students in South African HWIs is perhaps most pertinent to the complexity of studies on unbelonging and whiteness in South African higher education.

\section{The politics of belonging: As members of the Programme}

The association discussed above, between such designated groups and the Programmes, enabled microinvalidations which some of the participants believed followed Fellows throughout their career.

[Being selected for the Programme] allowed some to view me as 'unworthy' of my position. These prejudices are not new but they are also not being properly addressed as and when they are expressed.

Yet despite concerns about negative associations of being identified by others as a recipient of the Programme, two-thirds of the participants' positively identified as members of the Fellowship programme within the questionnaire responses. One of the participants explained how this seeming contradiction was possible, pointing to the contextual reception of the purpose of the Programme.

I am proud to be an appointee of a Programme designed to promote diversity (though how well it does is debatable) but I wish others at $\mathrm{X}$ $\{\mathrm{HWI}\}$ were informed about the value and necessity of such Programmes. I grew tired of having to justify my position and I no longer do so.

Both in the individual questionnaire responses and the small group discussions, participants reflected that individuals' interactions with other Fellows operated as spaces 
of solidarity. The formal and informal events, network gatherings and training-related interactions of the Programme, served as counter-spaces (Huber et al. 2015), allowing those Fellows marginalised by the norm of whiteness to develop momentary strategies for healing, empowerment, or building a sense of a possible future academic community.

However, some uncertainty was articulated by the white women Fellows. Their inclusion in the Programme was in a bid to address gender inequality in STEM disciplines. One of these Fellows provided more insight when this was discussed within the small groups,

I did not always understand what my role within this group was meant to be, so I was never sure if I was doing my bit or not. As a white woman, perhaps I felt like I did not deserve to be on the Programme.

The generally positive experiences of the participants encourage hope that a strong sense of engagement and validation could be realised. While identity pluralism allows for dominant and violent construction of identities to exist, it may make room for alternative and more inclusive identities to emerge.

Although the questionnaire did not ask for responses related to Fellows' identification with students within their departments and with student groups, this identification emerged within many of Fellows' open-ended responses as positive counter-spaces. At the margins of power in the institution, many of their narratives indicated a sense of solidarity with students at the fringes of academic citizenry where teaching-and-learning sites enabled teasing out the forging of their academic identities and critical pedagogy. This sense of the classroom as a site of struggle has been noted in marginal academic disciplines and in the critical tradition of adult education (Darder, 2012; hooks, 1989). Many of these staff cited examples about informal mentoring and support which they offered or were actively asked to provide, either by black students 
who sought those with similar cultural backgrounds (similar observations in Padayachee, 2015) or by their colleagues, who saw the Fellows as 'experts' of diversity and equity because of their inclusion in the Programme. Again, we found similarities of this emerging from US studies on faculty of colour (Stanley, 2006).

\section{The politics of belonging: As members of a department}

Academic development scholars have long noted that belonging to a community of practice within the academy, involves both idenfitication at professional, disciplinary levels and personal commitment; and that alienation at the departmental level may be detrimental to development (Bercher \& Trowler, 2001). Those more critical of 'academicity', recognise the identity constructions of being an academic as a colonialising process:

Academic subjectivation has been theorised as category boundary work requiring unequivocal and relentless annexation of the frontiers of academia (Petersen, 2007, p. 475).

The constrained academic territories (Charteris et al. 2017) to which mainstream staff are subjected in developed western contexts, is further rigidified by the unacknowledged elements of internalised inferiority of post-colonial intellectuals from cultural cringe (Phillips, 1950) and mental colonialization (Fanon, 1961). With less than two decades of massification and a strong tradition of autonomy in HWIs, there is resistance to the erosion of academic authority, and clinging to pre-war notions of 'the university' as the romanticised ideals of Oxbridge and Humboldt within South African research intensive universities. Editors of a seminal anthology on black academics within HWIs in the country have asked: "Can we really think of transforming our institutions without transforming the disciplinary communities to which we belong?" 
(Tabensky \& Matthews, 2015). Within this study, those Fellows who had been active in pursuing decolonial relations found the decolonial turn had little capital within their departments.

To some extent being involved in activities aimed at transformation, from a disciplinary perspective, are viewed as 'unnecessary distractions' in the pursuit of an academic career geared toward excellence regardless of the one's tone of skin or cultural heritage.

Within that complicated academic terrain, Fellows described how exclusionary institutional discourses, norms and practices further complicate the misrecognition (Fataar, 2018) of those of first-generation status from socially marginalised communities. Participants described how being black in white dominated departments often made Fellows feel imposters who had to constantly prove themselves.

The Programme often made me feel that I was illegitimate, and under surveillance - that I was viewed inherently as intellectually and professionally incompetent.

Most of the Fellows who were alumni of the institution were aware that they experienced less extreme microinvalidation in relation to their intellectual 'quality', compared to those who had studied elsewhere. However, even amongst the former, many felt they were not readily accepted as equally legitimate peers and experienced much patronising microinsults. For instance, one participant described how humiliating it was to be treated with "kid gloves" by his colleagues.

Those who felt most estranged were those who experienced microinvalidation of their research career and their disciplinary research interests. The excerpt below, from one of the Fellows who referred to 'resilience', articulated that, 
Your skin has to be elastic. Time and time again, I have been secondguessed, I'm just used to it, and don't let it bother me. So I let my work speak for itself.

A similar sense of having to work extra hard to prove themselves and 'let their work speak' among white colleagues, has similarly emerged in African American academics' narratives in predominantly white institutions in the USA (Stanley 2006).

Many Fellows expressed fatigue at playing the tacit rules of the game for acceptance as one of the departmental 'we'.

I do not know at what point I will crack the nod, if ever.

Collegiality is a complex concept in academia. In studies of US predominantly white institutions, the relationships of people of colour with colleagues either contributed to their success or were the tipping point for their leaving (Stanley 2006:714). The energy spent on working to interpret the tacit messages of expectations for collegiality contributed to POC's occupational stress.

In the context of these Programmes, the blurring of the formative and summative purposes served by departmental mentors within the Programmes, exacerbated the tensions between diverse interests, competing cultures and power dynamics within the Fellows' departments. Mentors were usually white, male, senior academics, tasked with both supporting and evaluating the quality of the Fellows. A participate articulated the voiceless conditions this dynamic created,

Conditions left me feeling as a newcomer that my voice could not penetrate a culture so 'sutured' and unchallenged by those acting as my mentors.

Some participants articulated that those mentors, who shielded mentees from being allocated heavy teaching loads, abuse, et cetera, had undertones of negativity and 
deficiency discourses in their benevolence. All those Fellows who had communicated their experiences of alienation and exclusion to their departmental colleagues, described how their feelings were downplayed as rejection-sensitivity or actively suppressed.

To provide insight into the fullness of what participants conveyed about their experiences of alienation within this category, we offer here focused discussion of one participant's story of 'oppositional positioning' (Sulé, 2014) and ensuing capitulation from 'battle fatigue' (Fasching-Varner, Albert, Mitchell, and Allen, 2014). While it is an individual's account, her story shared many similarities with those of the majority of black women participants in this study, and with other studies in the country where black woman academics have reported retreating to the margins to avoid victimization (Idahosa \& Vincent, 2014).

The Fellow narrated how when she first joined the department she articulated to her colleagues which microinsults she felt were unjust and unfair, in a bid to raise the consciousness of whiteness in her department. In response, she was labelled by colleagues as over-sensitive about things that were only about 'emotion'. She soon became characterised and dismissed as angry, argumentative and combative - irrational framing which carries historic associations of the angry black woman as hysterical. The marginality of women in academia has been a phenomenon documented since Victorian times (Hannan, 2014), particularly those with various additional markers of their difference (Idahosa \& Vincent, 2014; Sulé, 2014). Academic activist movements within South Africa, such as The Rhodes Must Fall movement, have drawn on the loaded cultural references to women as "our mothers", explicitly associated with "domestic workers, and the strong presence of women as spokespeople and protestors" (Coetzee, 2016, p. 207). 
By pathologizing this Fellow, white power retained social control in a pattern typical of such microinvalidation (Smith et al. 2016), leading to self-domestication "for the sake of peace". She narrated how she realised she was "meant to be seen but not heard", a description evoking the conditions of the reduced rights of children in authoritative families. Despite the supposed liberal orientation of her white colleagues, the common group identity approach to inclusion had dulled their obligation to act against the injustices she and other black colleagues were experiencing. Their capacity for empathy may have been stunted due to their apartheid upbringing and conditioning. Such principle-implementation gaps (Dixon et al., 2005, 2007), between those that profess to support equality but not social change in action, has been observed in studies in US contexts where emphasizing primarily common identity reduced whites' sensitivity to racial discrimination against blacks (Banfield, 2013). As an isolated agent in a hostile environment where self-validation was complicated by her dependence on mentorship figures who would summatively evaluate her performance, this Fellow felt she had little option but to choose self-preservation.

To change the way I was positioned (as this became emotionally draining), I chose to silence myself a lot of the time to avoid conflict and to integrate into the department and find some sort of sense of belonging. While I became an easier colleague to work with (as mentioned by many of my colleagues), I felt that I had compromised my own values, ethics and beliefs.

Within a year of articulating the experiences outlined above, this Fellow left the institution to work at a less prestigious institution, despite having initially been selected as a "rising star" and lauded by students as being "engaged" in her teaching while at the HWI. The excerpt below, from her correspondence with the authors about this paper, includes reflections about her experience within her department, and how it related to her sense of belonging in the institution, the subject of the next section. 
I don't really have anything to add or comment on [about the papers], except to say that I left X [HEI] traumatised and quite broken and am still recovering from that university. It's a toxic environment and there are no signs that it is going to change and those who should are not even willing to listen to the voices of marginalised groups. There is a lot of pretence from those in positions of power, but nothing real is ever done. Thinking about $\mathrm{X}$ $[\mathrm{HEI}]$ and my time there just makes me angry and sad, because, when I started working there, I had no idea what I was actually in for.

\section{The politics of belonging: As members of the institution}

In this section, we discuss how individuals' renegotiation of their identities was underlaid by tensions between institutional norms and individual values. LadsonBillings (1998) suggests that analysing positionality and difference within academic citizenship, is aided through the comprehension of citizenship as being grounded in differential experiences of rights. "One's sense of empowerment defines one's relation to law, in terms of trust \pm distrust, formality \pm informality, or right \pm no rights" (Williams 1995, p. 88 in Ladson-Billings 1998).

Fellows were employed on contracts of various lengths up to 3 years, following which there was the possibility for entry to the mainstream probation processes. This differed to the mainstream norm for the predominantly white staff, which was two years of probation, preceding tenure. The difference in this formal arrangement was often recounted directly to Fellows by academic colleagues and administrative staff, as one participant described,

I am told 'It is not a legitimate post, you're not academic staff'. I am not really AT this institution. Lots of loopholes are cited to avoid ensuring my job security after this contract.

Administrative and bureaucratic bungles, often related to financial matters, were commonplace features of all the Fellows' experiences. 
From an admin perspective, you're 'diversity'. Everything's a bit different. 'E-mail me tomorrow because this is a bit different'. The fact that you are this special individual who no-one actually really quite knows what to do with, um, kind of dis-empowers you.

Central to the structure of the Programme were staff appraisal practices to which each Fellow had to conform bi-annually to retain their contract. These evaluation processes were exponentially more rigorous than those imposed on mainstream tenured academics. Within the questionnaire responses, a number of participants discussed threats of disciplinary procedures for challenging authority, employment precarity and job loses for those seen as too challenging. Academic evaluation was similarly characterised as a "tool of fear" in US studies of Latinx academics (Urrieta et al, 2015, p. 1149). When discussing this at the small group discussions, one Fellow explained that

Staff who challenge or resist these traditional ways of being at the university are actively silenced and pressured to conform or face threats of disciplinary action. I need to tread carefully from now on if I want to have a future at this institution.

Performing to the expectation of such insidious evaluation practices and surveillance, did not necessarily lead to the anticipated gains in professional success, as this Fellow shared.

I have to admit to severe fatigue and a feeling of being constantly under scrutiny and seeing no results.

One participant recounted in the questionnaire that she even chose to withdraw from the Programme after a year of having participated, rather than have the stain of being associated with deficit. She chose instead to progress "the normal way" where her merit 
was not disparaged. The tendency for the dominant system/groups to engender assimilation over transformation was the dominant reason cited for the problem in the retention of black staff:

$\mathrm{X}[\mathrm{HEI}]$ has and will continue to see young black (and female) staff leave because the institutional culture is not one which values their voices. At best, we are supposed to reproduce old forms of knowledge productions from a 'different' perspective rather than being allowed to fundamentally question systemic forms.

Within a year of the initial data generation, a third of the study participants who had responded to the first stage were no longer at the institution. As one participant wry noted, the Programme was "not really a 'success' if retention is an issue". High levels of dissatisfaction, frequent job changes and less career advancement has similarly been noted among black academic staff compared to their white counterparts in the US (The Hechinger Report, 2014). For such experiences to persist within an African institution is deeply problematic, as this Fellow expressed.

Many young black staff feel that when transformation is pursued, that the integration of black staff is problematised as opposed to the environments that they are entering into.

\section{The costs of the politics of belonging}

Trapped in a system of exchange undertaken for strategic reasons to which they soon became disenchanted, Fellows' insights outlined in the section above indicated extreme experiences of alienation from their sense of self (Lukes, 1967) as they negotiated their subjugation as members of designated groups, fellows and academic citizens with less rights and affordances to flourish, than others. Fellows also experienced alienation from other human beings, because departmental colleagues acted 
as evaluator-mentors and there was hostility with dominant in-group members.

Relationships were no longer between academics but between the positions of power allotted by the social system.

However, a number of participants were able to chart ways in which they adapted to 'survive and thrive', attaining positions of tenure and power along the rugs of the academic hierarchy. One such Fellow explained that the burden she faced was not to be "labelled as the free riders without much contribution". The survive and thrive discourse has been critiqued for emphasizing resilience and coping mechanisms of individual agents, instead of altering the system (West-Olatunji, 2005). It does not develop the capacity for change in those responsible for creating negative experiences and cultures, nor hold them accountable. Many scholars of the critical tradition accuse the field of education for such psychologising, decontextualised emphases:

Only in a field that has obliquely refused to examine how extensively it contributes to societal disadvantage can those cast on the underside of humanity be told that they merely need to be grittier or have a growth mindset (Patel, 2016, 400).

Inclusion measures requiring resilience for adaption create invisible long-term negative effects on participants and their communities in the country. The negative outcomes of cumulative microaggressions include stress, anxiety, resentment, depression and isolation, subsequently leading to high attrition rates and low productivity for black academic staff (Williams \& Williams-Morris, 2000; Thompson, 2008; Sue, 2010). A number of the Fellows spoke of the cost of not 'surviving' within the parameters of this model. 
I am the cost, the casualty... I would rather not have to leave $\mathrm{X}$ but there is no space for me here... If you squash them hard enough, they'll fit. If I make myself less threatening, maybe they'll let me [in].

For many, the conditions were untenable and unsustainable. Recent cases of the suicides of black academics and students in South Africa (Dano, 2018) have brought such conditions into the public spotlight, bringing HWIs into disrepute. Student unrest since 2015 relates in part to such alienating meso-curricula cultures and 'black excellence' expectations within contexts of 'white mediocrity'. The systemic problem with the selfpreservation response mechanism, of assimilate and/or conform to the dominant world, is that the internalising of such microaggressions by such black academics may reproduce, and further add to the layers of intergenerational oppression enacted against their communities. Such culminative microaggressions reaffirm stereotypical images about blacks constructed by dominant members of society to maintain their power (Ladson-Billings, 1998), internalised as mental colonialization. These add further insult to injury if one considers the context is supposedly 'post'-colonial and 'post'-apartheid. Instead of the conditions for transformation, Fellows described how their energies were depleted by the debt of gratitude which their white counterparts imposed upon them. One shared how

... any efforts on my part to grow further in the institution from my point of reference were constantly strangled out by colleagues purporting that I ought to be grateful for even getting my foot in the door and should now assimilate and do the work I was hired to do as expected by the relevant power structures. Towards the end, I lost the zeal for my work and succumbed to the pressure in an attempt to retain my employment.

Silence about injustices can be attributed to the need to maintain 'cultural safety' (Tolich, 2002). Self-preservation is a response of compliance when one is bereft of the 
capacity for creativity (Winnicott, 1971). Consistent with these notions of alienation, some participants articulated how the fear of exclusion forced them to act in ways inconsistent with their self-image as change agents, and with their own desires about their research. Many of our participants' stories alluded to the loss of sense of self.

If we PERFORM a certain way, we are accepted... but who we ARE is so different to that.

This was in direct contradiction to the stated purposes of such Programmes in national discourses, which positioned such staff as change agents contributing to deracialising and degendering HE. One Fellow's articulation at a small group discussion elicited general agreement and an eruption of laughter by the participants, when pointing out the problematic nature of such assumptions.

Somehow this approach is supposed to bubble up and make the people who have the power to change suddenly dramatically change things. A part of it is somewhat, how shall I put it? Uh, almost colonial in going, 'Well listen, the natives know how to do this stuff, you know. And they're clearly all the same so it doesn't matter which one we ask, they will all tell us how to transform, because transformation is a thing that we can just ask any one of them. So surely if we ask ten of them - oh, no, we've got ten different answers, must be a data error. Let's have another round of dialogue'. The hot potato gets passed around to another committee, another group for next time, you know, for the real transformation to occur.

\section{Conclusions}

On an agential and cultural level, understanding and recognising one's experiences through storying, expressing emotions, aspirations and desires may result in a positive sense of belonging (Nussbaum, 2006). However, in contexts with legacies of intense 
inequality, conflict and oppression - such as the South African HE landscape of whiteness discussed in this paper - changing dominant discourses, norms and legitimations requires more radical approaches to disrupt the status quo (Nwadeyi, 2016). CRT can be constructively used to think about transformational projects in various ways, because dominant modes of thinking and the work of institutional structures may mask both the violence of microaggressions and the emancipatory possibilities that exist.

Microaggressions are racial symptoms of a larger disease (Huber et al. 2015) within South African society and the neoliberal academy. This study has aimed to identify the systemic nature of racism in these professional development initiatives in the South African academy, which have been mainstreamed despite the prevalence of current decolonising and democratising rhetoric in the sector. Emerging from this analysis of the experiences of macroaggressions within Fellows' experiences, are the consequences of a hidden curriculum of professional formation and socialisation in an HWI that by and large infanticises, domesticates, depoliticises and displaces the urgency for substantive change of the academy. The experiences of such black academics in South African institutions are of major concern because if such microaggressions are not addressed, they may have long-lasting effects on the mental health and the structural power of black academics as individuals within HWIs, and in turn, on what they may bring to legitimising African knowledge systems and ways of being in the academy. Microaggressions against such Fellows reflect structural and systematic oppression in the society more broadly, exacerbated by geopolitical inequalities and epistemicide.

When it comes to professional development and organizational leadership, the three foundational elements of intersectionality, participation, and accountability may 
better support a vision of social justice (McDowell et al. 2010). To facilitate positive long-term intergroup relations and social change, more complex representations of group identity is required which acknowledges both subgroups and superordinate identities (Banfield \& Dovido, 2013). Much interesting intellectual work is being done in this regard in relation to decoloniality. Strategies for addressing microaggressions require educating white colleagues about the covert forms of macroaggressions and creating the conditions for solidarity to address every day and systemic injustices. Researchers in critical Higher Education Studies require strategies and networks to develop a critical mass of evidence about macroaggressions, with cognisance of context, campus climate, and existing structures to address transformation challenges. Such efforts must be engaged with as the shared responsibility of those from all groups, in addition to those who wield power in higher education institutions (from mid-managers such as HoDs and Deans, to directors and Vice Chancellors) because 'power dynamics, positionality and authority can serve to deepen debates and policy directions in HEI' (Stanley, 2006).

In this study, experiences of self/identification, un/belonging and mis/recognition were shown to shape the different paths of identity formation, and consequently, individual, communal and structural norms of black academics' participation in this historically white institution. A central finding of the study was that accelerated development programme Fellows - as heterogeneous agents with multiple social, academic and cultural identities - increasingly contested the representations which had been imposed on them as members of the groups within which they were positioned. This contestation is in itself necessary for change. However, the need for covert operations, negotiations and adaption to survive departmental and institutional assimilation cultures, rings a death knell for the South African transformation agenda. 
In this study, our concern with microaggressions within the politics of belonging stems from a desire to trouble the continuation of the machinations of domination, and the privileges with which it is associated (Leonard, 2004).

\section{Acknowledgements}

The authors would like to thank the Fellows, for their willingness to contribute to this study, to challenge and deepen the analyses, and to educate us all with grace and generosity. GT thanks the Oppenheimer Memorial Trust for an Overseas Sabbatical Grant that allowed writing time at the Norwegian University of Life Sciences.

\section{Declaration of Interests Statement}

The authors have not benefited financially from this study.

\section{References}

Ahmed. S. \& Stacey, S. (2001). Thinking through the skin. London and New York: Routledge.

Arday, J. (2018). Understanding mental health: What are the issues for black and ethnic minority students at university? Social Sciences 7(10), 196.

Baldridge, B. J. (2016). 'It's like this myth of the supernegro': Resisting narratives of damage and struggle in the neoliberal educational policy context." Race Ethnicity and Education, 0(0), 1-15.

Banfield, J. C. \& Dovidio, J. F. (2013). White' perceptions of discrimination against Blacks: the influence of common identity. Journal of Experimental Social Psychology, 49(5), 833-841.

Belluigi, D. Z. \& Thondhlana, G. (2019). 'Why mouth all the pieties?' Black and women academics' revelations about discourses of 'transformation' at an historically white South African university. Higher Education, (online).

Belluigi, D. Z. \& Thondhlana, G. (In press). Transformation or 'training the dog'? Faculty insights into approaches to access and equity within an historically white institution in South Africa. 
Belluigi, D. Z. 'Practice-based reflections of enabling agency through arts-based methodological ir/responsibility' in Du, X. and Chemi, T. [Eds]. Arts-based methods in education around the world. River Publishers.

Becher, T. \& Trowler, P. (2001). Academic tribes and territories: Intellectual enquiry and the culture of disciplines. Maidenhead: Society for Research into Higher Education \& Open University Press.

Berry, T. R. (2017). The Intersections of Africana Studies and Curriculum Theory: A Counter-Western Narrative for Social Justice. Journal of Curriculum Theorizing 32(1), 53-66.

Bhopal, K., Brown, H., \& Jackson, J. (2018). Should I stay or should I go? In J. Arday \& H. S. Mirza (Eds.), Dismantling race in higher education. New York, NY: Springer Berlin Heidelberg.

Bhopal, K \& Pitkin, C. (2018). Investigating higher education institutions and their views on the race equality charter. University and College Union (UCU).

Bollinger, L. C. (2007). Why diversity matters. Chronicle of Higher Education, 35, no. 39: B20.

Burke, P. (2012). Widening participation in higher education: Racialized inequality and misrecognitions. In C. Alexander \& J. Ardey (Eds.), Aiming higher: Race, inequality and diversity in higher education (pp. 21-24). London, England: Runnymede Trust.

Coetzee, C. (2016). Academic Freedom in Contexts. Arts and Humanities in Higher Education, 15(2), 200-208.

Charteris, J., .Jones, M., Nye, A. \& Reyes, V. (2017). A Heterotopology of the Academy: Mapping assemblages as possibilised heterotopias. International Journal of Qualitative Studies in Education, 30(4), 340-53.

Christensen, A.-D., Jensen, S.Q., (2012). Doing Intersectional Analysis: Methodological Implications for Qualitative Research. NORA - Nordic Journal of Feminist and Gender Research, 20 (2), 109-125.

Clegg, S. (2009) Forms of knowing and academic development practice, Studies in Higher Education, 34 (4), 403-416.

Coleman, L. (2016). Offsetting deficit conceptualisations : methodological considerations for higher education research. Critical Studies in Teaching and Learning (CriSTaL), 4(1), 16-38. 
Collins, P. H. (1997). Comment on Heckman's 'Truth and method: Feminist standpoint theory revisited': Where's the power? Signs, 22, 375-381.

Dano, Z. 2018. Did student protests contribute to UCT professor's suicide? Cape Argus 30 July 2018

Darder, A. (2012). Neoliberalism in the academic borderlands: An on-going struggle for equality and human rights. Educational Studies, 48(5), 412-426.

Delgado, R. and Stefancic, J. (2001). Critical race theory: An introduction. New York: New York University Press.

DHET (Department of Higher Education and Training). (2015). Staffing South Africa's Universities Framework (SSAUF) - A comprehensive transformative approach to developing future generations of academics and building staff capacity. Pretoria, Department of Higher Education and Training.

DHET. (2017). Ministerial statement on the implementation of the university capacity development programme through effective management and utilisation of the University Capacity Development Grant 2018 - 2020. Pretoria. Department of Higher Education \& Training.

Dixon, J., Durrheim, K., \& Tredoux, C. (2007). Intergroup contact and attitudes toward the principle and practice of racial equality. Psychological Science, 18(10), 867872.

Dovidio, J. F., Kawakami, K., \& Gaertner, S. L. (2002). Implicit and explicit prejudice and interracial interaction. Journal of Personality and Social Psychology, 82(1), $62-68$.

Du Bois, W. E. B. (1903). The Souls of Black Folk. New York: Bantam Classic.

Erwin, K. (2012). Race and race thinking: Reflections in theory and practice for researchers in South African and beyond. Transformation: Critical Perspectives on Southern Africa, 79, 93-113.

Equity Challenge Unit. (2017). Equality in higher education statistical report 2017. https://www.ecu.ac.uk/about-us/he-equality-challenges/.

Fanon, F. (1961). The wretched of the earth. Translated from the French by Constance Farrington. New York: Grove Press.

Fataar, F. (2018) Placing students at the centre of the decolonizing education imperative: Engaging the (mis)recognition struggles of students at the postapartheid university, Educational Studies, 54:6, 595-608.

Freire, P. V. (1972). Pedagogy of the oppressed. Herder and Herder. 
Fasching-Varner. K., Albert, K. A., Mitchell, R. W. And Allen, C. Eds. (2014). Racial battle fatigue in higher education: Exposing the myth of post-racial America.. Lanham, Maryland: Rowman \& Littlefield Publishers.

Gillborn, D. (2005). Education policy as an act of white supremacy: Whiteness, Critical Race Theory and Education Reform. Journal of Education Policy, 20(4), 485505.

Gillborn, D. (2015). Intersectionality, Critical Race Theory, and the Primacy of Racism: Race, Class, Gender, and Disability in Education. Qualitative Inquiry, 21(3), 277-287.

Hall, J. M. \& Fields, B. (2015). It's killing us!” Narratives of black adults about microaggression experiences and related health stress. Global Qualitative Nursing Research, 1-14.

Hall, S. (1990). Cultural identity and diaspora. In Identity: Community, culture, difference, ed. Jonathan, Rutherford. London: Lawrence and Wishart.

Hannan, L. (2014). Collaborative scholarship on the margins: An epistolary network. Women's Writing, 21(3), 290-315.

Heleta, S. (2016). Decolonisation of higher education: Dismantling epistemic violence and eurocentrism in South Africa. Transformation in Higher Education, 1(1), 8.

hooks, b. (1989). Choosing the margin as a space of radical openness. Framework: The Journal of Cinema and Media, (36), 15-23.

Huber, L. P, \& Solorzano, D. G. (2015). Racial microaggressions as a tool for citical race research. Race, Ethnicity and Education, 18(3), 297-320.

Idahosa, G. \& L. Vincent. (2014). Losing, using, refusing, cruising: First-generation South African women academics narrate the complexity of marginality. Agenda, 28(1), 59-71.

Jansen, J. Ed. (2019). Decolonisation in universities: The politics of knowledge. Johannesburg, Wits Press.

Jawitz, J. (2012). Race and assessment practice in South Africa: Understanding black academic experience. Race Ethnicity and Education, 15(4), 545-559.

Keet, A. (2015). Annexure 10. Institutional cultures/ environments. Briefing paper prepared for the second Higher Education National Educational Transformation Summit. 15-17 October 2015. Durban. Available at https://www.academia.edu/24273943/Universities_-_Institutional_Cultures . Accessed 14 March 2019. 
Keet, A. \& Belluigi, D. (2019) Emancipatory Imaginations: Advancing Critical University Studies. Concept note to a Winter School held on 15-20 August 2019, Nelson Mandela University, Port Elizabeth. Available at https://crishet.mandela.ac.za/crishet/media/Store/documents/Concept\%20Note/C oncept-note-ACUS-Final.pdf . Accessed 20 December 2019.

Keet, A. \& Swartz, D. (2015). A Transformation Barometer for South African Higher Education. Draft Discussion Document for the Transformation Management Group of South African Universities. Available at http://www.usaf.ac.za/wpcontent/uploads/2016/09/Transformation-Barometer-_A-Discussion-Paper.pdf Accessed 8 April 2019.

Khunou, G., Phaswana, E., Khoza-Shangase, K. \& Canham, H. (2019). Black academic voices: The South African experience. Cape Town, HSRC Press.

Kitzinger, C. \& Wilkinson, S. (1993) The precariousness of heterosexual feminist identities, in: M. Kennedy, C. Lubelska \& V. Walsh (Eds) Making connections. London, Taylor \& Francis, 24-36.

Kravitz, D. A., Harrison, D. A., Turner, M. E., Levine, D. L., Chaves, A., Brannick, M. T., Denning, D. L., Russell, C. R., and Conard, M. A. (1997). Affirmative Action: A Review of Psychological and Behavioral Research. Bowling Green, $\mathrm{OH}$ : Society for Industrial and Organizational Psychology.

Ladson-Billings, G. (1998). Just what is critical race theory and what's it doing in a nice field like education? International Journal of Qualitative Studies in Education, 11(1), 7-24.

Langa, P. 2006. Transformative constitutionalism. Stellenbosch Law Review, 351. Ledesma, M.C., Calderón, D. (2015). Critical Race Theory in Education: A Review of Past Literature and a Look to the Future, Qualitative Inquiry 21, 3. 206-222.

Leonardo, Z. (2004). The Color of Supremacy: Beyond the Discourse of 'white privilege'. Educational Philosophy and Theory, 36(2), 137-52.

Louis, D. A., Rawls, G. J., Jackson-Smith, D., Chambers, G. A., Phillips, L. L.,\& Louis, S. L. (2016). Listening to Our Voices: Experiences of Black Faculty at Predominantly White Research Universities with Microaggression. Journal of Black Studies, 47(5), 454-474.

Lukes, S. (1967). Alienation and anomie. In P. Laslett \& Runciman (Eds.), Philosophy, Ethics and Society. Oxford: Basil Blackwell. 
Makhubela, M. (2018). “Decolonise, Don't Diversify": Discounting Diversity in the South African Academe as a Tool for Ideological Pacification. Education as Change, 22(1), 21.

Marginson, S. (2016). The worldwide trend to high participation higher education: dynamics of social stratification in inclusive systems. Higher Education, 72(4), 413-434.

Mbembe, A. (2015). "Decolonising Knowledge and the Question of the Archive." Lecture delivered at the Wits Institute for Social and Economic Research. Accessed January 19, 2017. http://wiser.wits.ac.za/sites/default/files/private/Achille\%20Mbembe\%20- 22 $\%$ 20Decolonizing\%20Knowledge\%20and\%20the\%20Question\%20of\%20the\% 20Arc hive.pdf.

McDowell, T., \& Hernández, P. (2010). Decolonizing academia: Intersectionality, participation, and accountability in family therapy and counseling. Journal of Feminist Family Therapy, 22(2), 93-111.

McKay, J., and M. Devlin. (2016). Low income doesn't mean stupid and destined for failure: challenging the deficit discourse around students from low SES backgrounds in higher education. International Journal of Inclusive Education, 20(4), 347-363.

Morrison. D., Annamma, S. A., \& Jackson,, D. D. (2017). Critical Race Spatial Analysis: Mapping to understand and address educational inequity. Stylus Publishing: Sterling VA.

National Centre for Education Statistics. (2017). The condition of education 2017 (NCES 2017-144), Characteristics of Postsecondary Faculty. U.S Department of Education.

Nussbaum, M. C. (2006). Education and democratic citizenship: Capabilities and quality education. Journal of Human Development, 7(3), 385-395.

Nwadeyi, L. C. (2016). Lovelyn Nwadeyi's empowering message: the onus is on us to disrupt the status quo. Mail \& Guardian, June 29. Analysis section.

O'Shea, S., P. Lysaght, J. Roberts, \& V. Harwood. (2016). Shifting the blame in higher education - social inclusion and deficit discourses. Higher Education Research \& Development, 35(2), 322-336.

Padayachee, K. (2015). Universities must rethink how they retain and nurture young academics. The Conversation. http://theconversation.com/universities-must- 
rethink-how-they-retain-and-nurture-young-academics-47894. Accessed 27 February 2017

Palmer, R. T. (2019). Are You Serious About Diversifying Your Faculty and Staff? Inside HigherEd. October 21, 2019. Accessed 19 January 2020. Available at https://www.insidehighered.com/views/2019/10/21/recommendationsinstitutions-diversifying-their-faculty-and-staff-opinion

Patel, L. (2016). Pedagogies of resistance and survivance: Learning as marronage. Equity \& Excellence in Education, 49(4), 397-401.

Petersen, E. B. (2007). Negotiating academicity: Postgraduate research supervision as category boundary work. Studies in Higher Education, 32(4), 475-87.

Phillips, A. (1950). The cultural cringe. Meanjin 9(4), 299-302.

Pierce, C. (1969). Is bigotry the basis of the medical problem of the ghetto? In Medicine in the Ghetto, edited by J. Norman, 301-314. New York: Meredith Corporation.

Pieterse A. L., Todd N. R., Neville H. A., \& Carter R. T. (2012). Perceived racism and mental health among Black American adults: A meta-analytic review. Journal of Counselling Psychology, 59, 1-9.

Pittman, C.V. (2012). Racial microaggressions: The narratives of African American faculty at a predominantly white university. The Journal of Negro Education, 81(1), 82-92.

Profit, W., Mino, I. \& Pierce, C.. (2000). Blacks, Stress. in. In Encyclopaedia of Stress. Vol. 1 (A-D), edited by G. Fink, 324-330. San Diego, CA: Academic Press.

Purdie-Vaughns, V., \& Eibach, R. P. (2008). Intersectional invisibility: The distinctive advantages anddDisadvantages of multiple subordinate-group identities. Sex Roles, 59(5-6), 377-391.

Republic of South Africa. (1998). Employment equity Act No 55. Cape Town: Government Gazette 400 No. 19370.

Savas, G. (2014). Understanding critical race theory as a framework in higher educational research. British Journal of Sociology of Education, 35(4), 506-522.

Smith, W. A., J. B. Mustaffa, C. M. Jones, T. J. Curry, and W. R. Allen. (2016). You make me wanna holler and throw up both my hands!': campus culture, Black misandric microaggressions, and racial battle fatigue. International Journal of Qualitative Studies in Education, 29(9), 1189-1209. 
Soudien, C. (2010). Grasping the nettle? South African higher education and its transformative imperatives. South African Journal of Higher Education, 24(6), 881-896.

Spivak, G. C. (2008). Outside in the Teaching Machine. New York, NY: Routledge.

Stanley, C. A. (2006). Coloring the academic landscape: Faculty of color breaking the silence in predominately White colleges and universities. American Educational Research Journal, 43, 701-736.

Stronach, I., \& Piper, H. (Eds.). (2004). Educational Research: Difference and Diversity. Burlington, Vt: Ashgate.

Sue, D. W. (2010). Microaggressions in everyday life: Race, gender and sexual orientation. Hoboken, NJ: John Wiley.

Sulé, V. T. (2014). Enact, discard, and transform: a critical race feminist perspective on professional socialization among tenured Black female faculty. International Journal of Qualitative Studies in Education, 27(4), 432-453.

Suransky, A., and J. C. van der Merwe. (2016). Transcending apartheid in higher education: transforming an institutional culture. Race, Ethnicity and Education, 19(3), 577-597.

Tabensky, P., \& Matthews, S. (Eds.). (2015). Being at home: Race, institutional culture and transformation at South Africa's higher education institutions. Pietermaritzburg, South Africa: University of KwaZulu-Natal Press.

Tate, S. A. \& Bagguley, P. (2017). Building the anti-racist university: next steps. Race, Ethnicity and Education 20, no. 3: 289-299.

Taylor, E. (1998). A primer on critical race theory: Who are the critical race theorists and what are they saying? Journal of Blacks in Higher Education, 122-124.

The Hechinger Report. (2014). Covering innovation and inequality in education. 23 September 2014. https://hechingerreport.org/

Thompson, C. (2008). Recruitment, retention, and mentoring faculty of color: The chronicle continues. New Directions for Higher Education, 143, Wiley Periodicals online.

Thondhlana, G. \& Belluigi, D. Z.. 2016. Students' reception of peer assessment of group-work contributions: Problematics in terms of race and gender emerging from a South African case study. Assessment \& Evaluation in Higher Education, 42(7), $1118-1131$. 
Tolich, M. (2002). Pakeha 'paralysis': cultural safety for those researching the general population of Aotearoa. Social Policy Journal of New Zealand, 19, 164-178.

Transformation Strategy Group. (2017). Transformation barometer framework.

Universities South Africa. http://www.usaf.ac.za/wpcontent/uploads/2016/09/Transformation-Barometer-Framework.pdf. Accessed 21 November 2018.

Trejo, J. (2017). A reflection on faculty diversity in the 21st century. Molecular biology of the cell, 28(22), 2911-2914.

United Nations. (2015). Transforming our world: The 2030 agenda for sustainable development. A/RES/70/1.

https://sustainabledevelopment.un.org/content/documents/21252030\%20Agenda \%20for\%20Sustainable\%20Development\%20web.pdf. Accessed 12 January 2018.

Urrieta, L. Jnr., Méndez, L., \& Rodríguez, E. (2015). 'A moving target': A Critical Race analysis of Latina/O faculty experiences, perspectives, and reflections on the tenure and promotion process. International Journal of Qualitative Studies in Education, 28(10), 1149-68.

Walker, M. (2005). Rainbow nation or new racism? Theorizing race and identity formation in South African higher education. Race, Ethnicity and Education, $8(2), 129-146$.

West-Olatunji, C. (2005). Incidents in the lives of Harriet Jacobs -- a readers theatre: Disseminating the outcomes of research on the Black experience in the academy. In J. King (Ed.), Black education: A transformative research and action agenda for the new century (pp. 329-340). Mahwah, NJ: Lawrence Erlbaum Associates Publishers.

Williams D. R., \& Williams-Morris R. (2000). Racism and mental health: The African American experience. Ethnicity \& Health, 5, 243-268

Winnicott, D. W. (1971). Playing and Reality. London: Tavistock.

Williams, P., Bath, S., Arday, J., \& Lewis, C. (2019). The broken pipeline: Barriers to Black PhD students accessing research council funding. Leading Routes.

Young, K., Anderson, M., \& Stewart, S. (2015). Hierarchical microaggressions in higher education. Journal of Diversity in Higher Education, 8(1), 61-71.

Yuval-Davis, N. 2006. Belonging and the politics of belonging. Patterns of Prejudice, 40(3), 197-214. 
${ }^{\mathrm{i}}$ We are somewhat bound to these problematic constructions of race, as they are consistent with the classifications of the national equity discourses of the study context (Republic of South Africa, 1998), in addition to the criteria for selection of our participants to these Programmes. We use the racial distinction 'white', 'black', 'Indian' and 'coloured' to define South African citizens according to their descent as Caucasian, black, western Asian descent and the so called 'mixed race' respectively.

${ }^{i i}$ For the most part, these Programmes have included black academics. Less common, was the selection of white women academics where gender diversity was to be addressed at departmental level. More recently, policies have regulated the inclusion of black academics who are citizens of countries outside of South Africa, with a preference for South African 'nationals'.

iii Across its purposes of public, private and common good, HE has a role for each of the Sustainable Development Goals (SDGs). It has a direct relation to the aim of Sustainable Development Goal (SDG) 4 to "ensure inclusive and equitable quality education and promote lifelong learning opportunities for all"; a responsibility to address gender inequality and contribute to the empowerment of women (SDG 5); an influential role in SDG 8 promotion of "sustained, inclusive and sustainable economic growth, full and productive employment and decent work for all"; and arguably a role of moral authority in to both "promote peaceful and inclusive societies for sustainable development, provide access to justice for all and build effective" and to practice "accountable and inclusive institutions at all levels" (SDG 16) to be fit-for-purpose (United Nations, 2015).

iv The research received ethical clearance from the department responsible for facilitating and supporting the Programme Fellows at the institution. Consistent with ethical standards, the objectives and purpose of the research and anonymity and confidentiality of responses were explained to prospective respondents before the study, and the study was conducted with the respondents' informed consent. The identity of the participants, their respective departments and institution have been protected due to the professional risk involved. 